\title{
BIODEGRADAÇÃO DE TOLUENO E ÓLEO DE PESCADO EM SOLOS IMPACTADOS UTILIZANDO SURFACTANTES QUÍMICO E BIOLÓGICO
}

\author{
Vanessa Sacramento Cerqueira e Jorge Alberto Vieira Costa* \\ Escola de Química e Alimentos, Universidade Federal do Rio Grande, CP 474, 96201-900 Rio Grande - RS, Brasil
}

Recebido em 12/5/08; aceito em 12/9/08; publicado na web em 5/2/09

\begin{abstract}
BIODEGRADATION OF TOLUENE AND FISH OIL IN IMPACTED SOIL USING CHEMICAL AND BIOLOGICAL SURFACTANTS. The process of biodegradation of soils contaminated by animal (raw fish oil) and mineral (toluene) origin compounds was studied, verifying the influence of adding biosurfactants and chemical surfactants and nutrients in the media. The highest removal rate of fish oil was $59.47 \%$ obtained in the experiments containing biosurfactant and biostimulate in 90 days process. The highest removal rate of toluene was achieved in 14 days for experiments containing biosurfactant, chemical spreading and biosurfactant with biostimulation, showing great influence of evaporation on the process. The use of surfactants has shown to increase the contaminant bioavailability due to its higher degradation rate.
\end{abstract}

Keywords: biodegradation; biosurfactants; soil.

\section{INTRODUÇÃO}

A contaminação do ar, solos, sedimentos, águas subterrâneas e superficiais por compostos orgânicos tóxicos tornou-se um dos maiores problemas enfrentados pelo mundo industrializado. Nas últimas décadas, uma ampla variedade de substâncias tóxicas e perigosas tem sido introduzida no meio ambiente, em especial, aquelas decorrentes de despejos de efluentes industriais e as provenientes de acidentes envolvendo derrames de petróleo e seus derivados. O aumento dos problemas ligados à poluição ambiental tem acarretado em uma maior conscientização quanto à importância da restrição de lançamentos indiscriminados de poluentes e da necessidade de remediar esses locais impactados. ${ }^{1}$

Os resíduos líquidos gerados pelas indústrias químicas e de alimentos apresentam grande complexidade física e química, o que dificulta seu tratamento, podendo causar riscos ao meio ambiente onde são descartados.

Em relação aos compostos de origem mineral, os derrames, tanto na exploração quanto no transporte, e os rejeitos produzidos nas atividades de refino incorporam-se ao meio ambiente natural em grandes volumes, ocasionando o acúmulo de uma grande quantidade de contaminantes. ${ }^{2} \mathrm{~A}$ gasolina, por exemplo, é uma mistura complexa de hidrocarbonetos com diferentes graus de volatilização, como compostos alifáticos (alcanos, cicloalcanos e alquenos), aromáticos (benzeno, etilbenzeno, tolueno e xilenos - BTEX) e aditivos, com cadeias carbônicas compreendidas na faixa de 5 a 10 carbonos por molécula. Dentre os hidrocarbonetos, os monoaromáticos BTEX têm maior solubilidade em água e, portanto, são os poluentes que primeiro irão atingir o lençol freático. ${ }^{3}$ Os compostos BTEX podem causar sérios riscos à saúde humana, principalmente devido ao caráter tóxico, mutagênico e carcinogênico.

A elevada potencialidade do uso de microrganismos como agentes degradadores das mais diversas substâncias, aliada ao emprego da biotecnologia, indicam o tratamento biológico como um dos mais eficientes métodos para se reduzir os efeitos adversos dos contaminantes sobre o meio ambiente. ${ }^{4}$ Os sistemas biológicos são utilizados para tratar a poluição e restaurar a qualidade ambiental por meio da degradação dos poluentes. Este processo vem se destacando pois, além de eliminar o poluente de forma menos agressora, é também

\footnotetext{
*e-mail: jorgealbertovc@ terra.com.br
}

tipicamente mais econômico que métodos tradicionais. ${ }^{5}$

A introdução de nutrientes adicionais (bioestimulação), como nitrogênio e fósforo, na forma orgânica e/ou inorgânica no sistema contaminado, tem mostrado o aumento da população de microrganismos endógenos e, assim, o aumento da taxa degradativa do contaminante. ${ }^{6}$

Evidências sugerem que, em ambientes aquáticos e terrestres, os microrganismos são os agentes principais para a biodegradação de moléculas de interesse ambiental. Bactérias e leveduras parecem ser os degradadores dominantes em ecossistemas aquáticos, enquanto fungos e bactérias são os principais degradadores em solos. No entanto, a degradação de contaminantes parece envolver o consórcio de microrganismos, incluindo formas eucarióticas e procarióticas, e não somente uma única espécie de microrganismo. ${ }^{7}$

A intensidade de biodegradação pode ser influenciada por diversos fatores, tais como nutrientes, oxigênio, $\mathrm{pH}$, características químicas e físicas dos ambientes contaminados, composição, concentração e biodisponibilidade dos contaminantes. ${ }^{8}$ A baixa disponibilidade de muitos dos contaminantes do solo aos microrganismos é um dos principais fatores que interferem no processo de biodegradação. ${ }^{4}$ Uma alternativa de incremento da metabolização e da possibilidade de biodegradação dos contaminantes é aumentar a solubilização destes substratos empregando-se surfactantes e emulsificantes. ${ }^{4}$

Surfactantes são moléculas orgânicas que usualmente consistem de uma porção hidrofóbica e outra hidrofílica, e apresentam a capacidade de atuar na interface de compostos de diferentes naturezas. ${ }^{9}$ Os surfactantes, em particular, podem interagir com os compostos presentes e aumentar sua solubilidade em água. Desta forma, a presença de surfactantes, naturais ou sintéticos, aumenta a disponibilidade dos contaminantes aos microrganismos e, conseqüentemente, à biodegradação. ${ }^{4}$

Tendo em vista as crescentes preocupações ambiental, econômica e social, a questão da utilização de surfactantes biológicos tem recebido grande interesse devido a características que os tornam vantajosos frente aos surfactantes químicos. Dentre estas, baixa toxicidade, biodegradabilidade e síntese a partir de material renovável e de baixo custo são fatores que tornam desejável a substituição dos compostos quimicamente sintetizados. ${ }^{10}$

O município do Rio Grande, localizado no extremo sul do Brasil, apresenta-se como importante pólo industrial, caracterizado pela presença de indústrias de médio e grande porte. Localizado na extremidade final 
da Lagoa dos Patos, na interação dos ecossistemas formados por Oceânico Atlântico, lacustre e estuariano-lagunar, destaca-se por possuir um dos maiores portos do país. A zona portuária da cidade do Rio Grande apresenta constante movimentação de embarcações e cargas provenientes de indústrias e caracteriza-se por apresentar em sua costa a instalação de diversas empresas do setor alimentício, como a industrialização de pescado, e também na área química, como fertilizantes, petróleo e seus derivados (refino e armazenamento). Devido à sua localização, o Estuário da Lagoa dos Patos está exposto a diversas ocorrências de poluição, seja pela eliminação de rejeitos industriais, ou por derrames de óleos causados durante o processo, refino e transporte.

Tendo em vista a problemática causada aos ecossistemas marinhos e terrestres devido à poluição por atividades industriais e na área portuária, torna-se de extrema importância a aplicação de medidas corretivas para a rápida remoção de forma menos agressora ao meio ambiente.

O objetivo deste trabalho foi estudar a biodegradação de compostos de origem animal e mineral em solos contaminados por tolueno e óleo de pescado, avaliando o efeito da adição de biossurfactantes e surfactantes químicos e adição de nutrientes no meio.

\section{PARTE EXPERIMENTAL}

\section{Coleta das amostras de solo}

A coleta do solo foi realizada no Estuário da Lagoa dos Patos, junto ao terminal portuário da empresa COPESUL (Companhia Petroquímica do Sul), localizado na região sul do estado do Rio Grande do Sul, Brasil, latitude $32^{\circ} 04^{\prime} 09^{\prime}$ 'S e longitude $52^{\circ} 05^{\prime} 15^{\prime \prime} \mathrm{W}$.

\section{Caracterização do solo}

A classificação geral do solo foi feita através de peneiramento utilizando peneiras com Tyler entre 8 e 200 (2,360 e $0,075 \mathrm{~mm}$, respectivamente), sendo a massa retida em cada uma das peneiras comparada à escala de Wentworth. ${ }^{11}$

\section{Montagem dos experimentos}

Para o estudo de biodegradação de óleo de pescado em solos foram realizados 6 experimentos e para o estudo de biodegradação de tolueno foram realizados 7 experimentos, conforme mostrado na Tabela 1, ao longo de 90 dias. O experimento 7 foi realizado utilizando solo estéril. A esterilização do solo foi realizada em autoclave a $121{ }^{\circ} \mathrm{C}$ durante $90 \mathrm{~min}$.

Os ensaios foram realizados em recipientes de vidro com dimensões 0,25 x 0,25 x 0,25 m contendo 5,82 $\mathrm{kg}$ de solo, correspondendo

Tabela 1. Experimentos de biodegradação realizados em solos para cada composto estudado

\begin{tabular}{lcc}
\hline Experimento & Surfactante & Bioestimulação \\
\hline 1 (Controle) & Ausência & Ausência \\
2 & Ausência & Presença \\
3 & Biossurfactante & Ausência \\
4 & Surfactante químico & Ausência \\
5 & Biossurfactante & Presença \\
6 & Surfactante químico & Presença \\
${ }^{*} 7$ (Branco) & Ausência & Ausência \\
\hline
\end{tabular}

*Experimento realizado somente no estudo de biodegradação de tolueno a uma altura de $0,07 \mathrm{~m}$. Foram simulados derrames de compostos de diferentes naturezas, óleo de pescado bruto e tolueno, na proporção de $4 \%$ em relação ao peso seco de solo.

O conteúdo de água adicionado aos experimentos foi ajustado para que todos os experimentos apresentassem o mesmo teor inicial de umidade (12\%). A cada 7 dias, os solos foram revolvidos, para fornecer oxigênio ao meio.

Os experimentos foram mantidos em local protegido de intempéries e a temperatura monitorada ao longo do tempo.

\section{Surfactante}

Foram testados surfactantes de diferentes naturezas, microbiológico (biossurfactante) e químico (dispersante). A quantidade de surfactante adicionado foi calculada com base na sua atividade emulsificante $(50 \%)$ determinada ao início dos experimentos.

Inicialmente foi determinada a atividade emulsificante utilizando biossurfactante. Para isto, foi adicionado em tubo de ensaio, o composto em estudo e biossurfactante na proporção de 1:1. Posteriormente o tubo foi agitado em agitador vortex durante 1 min e deixado em repouso durante $24 \mathrm{~h}$. Após este período, foi realizada a medida da altura da fase emulsionada e do composto não emulsificado. A relação entre a altura emulsificada e a altura total foi determinada como a atividade emulsificante, dada pela Equação 1:

Atividade emulsificante $(\%)=(\mathrm{He} /(\mathrm{He}+\mathrm{Hc})) \times 100$

onde He corresponde à altura da emulsão $(\mathrm{cm})$ e Hc, à altura do composto $(\mathrm{cm}) .^{12}$

O mesmo procedimento foi realizado para diferentes diluições do dispersante químico a fim de estabelecer uma diluição que promovesse a mesma atividade emulsificante obtida com o biossurfactante. A diluição de 1:100 (dispersante químico: água destilada) foi a que promoveu a mesma atividade emulsificante, sendo a escolhida para o derrramamento.

\section{Produção de biossurfactante}

O biossurfactante foi obtido a partir do fungo filamentoso Aspergillus fumigatus, cedido pelo Laboratório de Microbiologia de Alimentos, Faculdade de Engenharia de Alimentos, Universidade Estadual de Campinas (UNICAMP), através de fermentação em estado sólido. A propagação do inóculo foi feita através da técnica de espalhamento em superfície realizada em frascos de Roux contendo ágar batata-dextrose (PDA) adicionado de $1 \%$ de glicerina e $0,5 \%$ de ágar-ágar. Os frascos de Roux foram mantidos em estufa a $30{ }^{\circ} \mathrm{C}$ durante 7 dias, visando o recobrimento completo da superfície e a esporulação total dos microrganismos. Após este período, foi realizada a raspagem dos esporos e posterior filtração. Na suspensão obtida foi realizada a contagem de esporos em câmara de Neubauer. ${ }^{13}$

As fermentações foram realizadas em biorreatores tipo coluna de leito fixo, com dimensões internas 50 x $250 \mathrm{~mm}$ (diâmetro x altura), durante $144 \mathrm{~h}$, mantidos a $30^{\circ} \mathrm{C}$, pela circulação de água através do encamisamento do biorreator. $\mathrm{O}$ ar fornecido ao sistema foi controlado através de rotâmetros previamente calibrados, utilizando taxa de aeração de $60 \mathrm{~mL} \mathrm{~g}^{-1} \mathrm{~h}^{-1}$. O meio fermentativo foi constituído por casca de arroz e farelo de trigo nas proporções 15 e $85 \%$, respectivamente. $\mathrm{O}$ farelo de trigo foi peneirado e foram recolhidas as partículas com granulometria entre 0,710 e 1,000 mm (Tyler 24 e 16, respectivamente). Foi adicionada à mistura da casca e farelo uma solução nutriente composta por: $0,5 \mathrm{~g}$ de $\mathrm{MgSO}_{4} .7 \mathrm{H}_{2} \mathrm{O}, 3 \mathrm{~g}$ de $\mathrm{NaNO}_{3}, 1 \mathrm{~g}$ de $\mathrm{KH}_{2} \mathrm{PO}_{4}$, $1 \mathrm{~g}$ de extrato de levedura e $0,3 \mathrm{~g}$ de peptona em $1 \mathrm{~L}$. O meio foi ajustado para umidade de $50 \%$ e $\mathrm{pH} 4,5$. Foi adicionado ao meio, $1 \%$ 
de tolueno como fonte adicional de carbono. Após o preparo do meio foi realizada, em ambiente asséptico, a inoculação do microrganismo na concentração de 4 x $10^{6}$ esporos/g de meio.

A extração do biossurfactante do farelo fermentado foi realizada com água destilada a $90{ }^{\circ} \mathrm{C}$ na proporção de 1:9 (uma parte de soluto para nove partes de solvente). Posteriormente, a amostra foi submetida à agitação em Shaker (B. Braun Certomat BS-1, Alemanha) a $160 \mathrm{rpm}$ e $50{ }^{\circ} \mathrm{C}$ durante $30 \mathrm{~min}$, sendo em seguida filtrada a vácuo.

\section{Dispersante químico}

Foi usado dispersante químico comercial com permissão do Instituto Brasileiro do Meio Ambiente (IBAMA) para ser utilizado em possíveis derramamentos. ${ }^{14} \mathrm{~A}$ Tabela 2 apresenta as propriedades físico-químicas do dispersante químico. $\mathrm{O}$ dispersante foi diluído em água (1:100) para proporcionar a mesma atividade emulsificante $(50 \%)$ do biossurfactante.

Tabela 2. Propriedades físico-químicas do dispersante químico utilizado

\begin{tabular}{lc}
\hline Propriedade & Característica \\
\hline Aspecto & Líquido amarelado \\
$\mathrm{pH}$, solução aquosa $5 \%, 25{ }^{\circ} \mathrm{C}$ & 6 \\
Densidade, $20{ }^{\circ} \mathrm{C}, \mathrm{g} / \mathrm{cm}^{3}$ & 0,99 \\
Viscosidade $\mathrm{BKF}, 20^{\circ} \mathrm{C}, \mathrm{cP}$ & 100 máx. \\
Matéria ativa, $\%$ & 35 \\
Ponto de fulgor, $\mathrm{VF}\left({ }^{\circ} \mathrm{C}\right)$ & 73,2 \\
\hline
\end{tabular}

\section{Bioestimulação}

Nos experimentos em que os solos foram bioestimulados foi feita a adição dos fertilizantes uréia ( $46 \%$ de N) e TSP (Superfosfato triplo, $46 \%$ de $\mathrm{P}_{2} \mathrm{O}_{5}$ ) na proporção de 100:15:3 (C:N:P), tendo como base a quantidade de carbono do derrame. Os fertilizantes foram moídos e posteriormente diluídos em água destilada estéril.

\section{Amostragem}

Os experimentos foram realizados durante 90 dias, sendo coletadas amostras nos dias $0,7,14,21,30,60$ e 90 para a análise de degradação do óleo de pescado, nos dias 0, 4, 7, 14, 21, 30, 60 e 90 para a análise de degradação do tolueno, nos dias $0,7,15,30,60$ e 90 para a análise microbiológica e nos dias 0,45 e 90 para a análise do conteúdo de nitrogênio e fósforo total.

As amostras foram coletadas a partir da superfície até uma profundidade de $0,07 \mathrm{~m}$ em 5 pontos distintos, sendo posteriormente homogeneizadas. As amostras para a análise microbiológica foram acondicionadas em frascos de vidro âmbar estéreis providos de tampa de rosca e imediatamente processadas. As amostras destinadas às análises de teor de nitrogênio e fósforo total e de degradação dos contaminantes foram armazenadas em frascos de vidro âmbar estéreis cuidadosamente vedados com batoque e providos de tampa de rosca. Para a análise da degradação de óleo de pescado, as amostras foram congeladas e processadas em um período máximo de 7 dias. No caso da degradação do tolueno, as amostras foram refrigeradas e enviadas à empresa COPESUL localizada na cidade de Triunfo/RS, onde foram mantidas refrigeradas, sendo processadas em um período máximo de 7 dias. Para a análise de nitrogênio e fósforo total as amostras foram mantidas refrigeradas e analisadas em um período máximo de 10 dias. Durante a amostragem foi realizado o controle da temperatura ambiente.

\section{Análises de biodegradação dos compostos}

Para a determinação da degradação do óleo de pescado, as amostras de solo foram descongeladas à temperatura ambiente e secas a $105^{\circ} \mathrm{C}$ por $1 \mathrm{~h}$. A extração do óleo foi realizada em extrator de Soxhlet por $6 \mathrm{~h}$, sendo utilizado hexano como solvente. Posteriormente, no extrato lipídico seco realizou-se a saponificação e esterificação (metilação) para a obtenção dos metil-ésteres dos ácidos graxos, seguida de cromatografia gasosa, a fim de se determinar o perfil de ácidos graxos do óleo. ${ }^{15}$

A determinação dos ácidos graxos foi realizada em cromatógrafo a gás modelo 3400-Varian equipado com detector de ionização de chama e coluna capilar modelo CPSil 88. O gás de arraste foi hidrogênio UP fluxo a $1,0 \mathrm{~mL} \mathrm{~min}^{-1}$. Os ácidos graxos foram identificados pela comparação dos tempos de retenção com padrões e quantificados por normalização de áreas. Foram utilizados padrões diluídos em hexano e foi injetado $1 \mu \mathrm{L}$.

A determinação da concentração de tolueno foi feita em cromatógrafo a gás equipado com detector de ionização de chama e coluna capilar de metil silicone, utilizando amostrador headspace. ${ }^{16.17} \mathrm{~A}$ concentração dos componentes da amostra foi calculada por padronização externa, a partir de uma mistura padrão, preparada em matriz de natureza similar à da amostra e concentração próxima à dos constituintes a serem determinados. A partir dos resultados de concentração do composto nos diferentes tempos de amostragem, calculou-se a eficiência de remoção do composto através da Equação 2:

Eficiência $(\%)=\left(\left(\mathrm{C}_{\mathrm{x}}-\mathrm{C}_{\mathrm{y}}\right) / \mathrm{C}_{\mathrm{x}}\right) * 100$

onde C é a concentração do composto ( $\mathrm{mg} / \mathrm{kg}$ ); e $x$ e $y$ é o tempo de amostragem (dias).

\section{Análises microbiológicas}

A contagem de microrganismos no solo foi estimada através do método de NMP (número mais provável) ${ }^{18}$ Primeiramente, a amostra de solo foi homogeneizada com água destilada estéril na proporção de 1:9 em Blender durante 2 min. Posteriormente procederam-se diluições até $10^{-8}$ em placas de cultivo de 24 poços.

Para a determinação de microrganismos heterotróficos totais, foi utilizado o meio R2A ( $250 \mu \mathrm{L})$ em placas de cultivo de 96 poços, adicionado de $10 \mu \mathrm{L}$ de cada diluição. As placas foram incubadas a $30{ }^{\circ} \mathrm{C}$ durante 14 dias e o crescimento microbiano foi determinado por turbidimetria. Para a determinação de microrganismos degradadores de hidrocarbonetos foi utilizado o meio Bushnell-Hass e uma solução de cloreto de tetrazólio (TTC) como indicador. Após a inoculação $(10 \mu \mathrm{L})$ de cada diluição, as placas foram inoculadas com $10 \mu \mathrm{L}$ de tolueno. As placas foram incubadas a $30^{\circ} \mathrm{C}$ durante 14 dias e o crescimento microbiano foi determinado por desenvolvimento de cor violeta (indicando redução do indicador via respiração). ${ }^{19}$ Para a determinação de fungos foi utilizado o meio Czapek's, adicionado de $10 \mu \mathrm{L}$ de cada diluição. As placas foram incubadas a $30^{\circ} \mathrm{C}$ durante 14 dias e o crescimento microbiano foi determinado por turbidimetria. A população microbiana foi então determinada usando-se tabelas de NMP. ${ }^{20}$

\section{Análises de nitrogênio e fósforo total}

A determinação de nitrogênio total foi realizada pelo método de Micro-Kjeldhal e a determinação de fósforo total através de método colorimétrico utilizando molibdato de amônio. ${ }^{21}$

\section{RESULTADOS E DISCUSSÃO}

Os experimentos foram realizados em sistemas abertos e em local 
protegido de intempéries. A temperatura local foi monitorada ao longo do processo, sendo a mínima 14 e a máxima $28^{\circ} \mathrm{C}$.

O solo utilizado nos experimentos foi classificado como areia fina, com composição de $3,44 \%$ de grão, $1,15 \%$ de areia muito grossa, $18,43 \%$ de areia grossa, $14,20 \%$ de areia média, $59,01 \%$ de areia fina e $3,77 \%$ de areia muito fina.

\section{Análises microbiológicas}

A população microbiana presente nos solos foi monitorada durante 90 dias de experimento. A Figura 1 mostra os valores encontrados da enumeração de microrganismos heterotróficos totais e fungos para os experimentos com derrames de óleo de pescado bruto. A Figura 2 mostra os valores encontrados de microrganismos heterotróficos totais, fungos e microrganismos degradadores de hidrocarbonetos para os experimentos contendo tolueno.
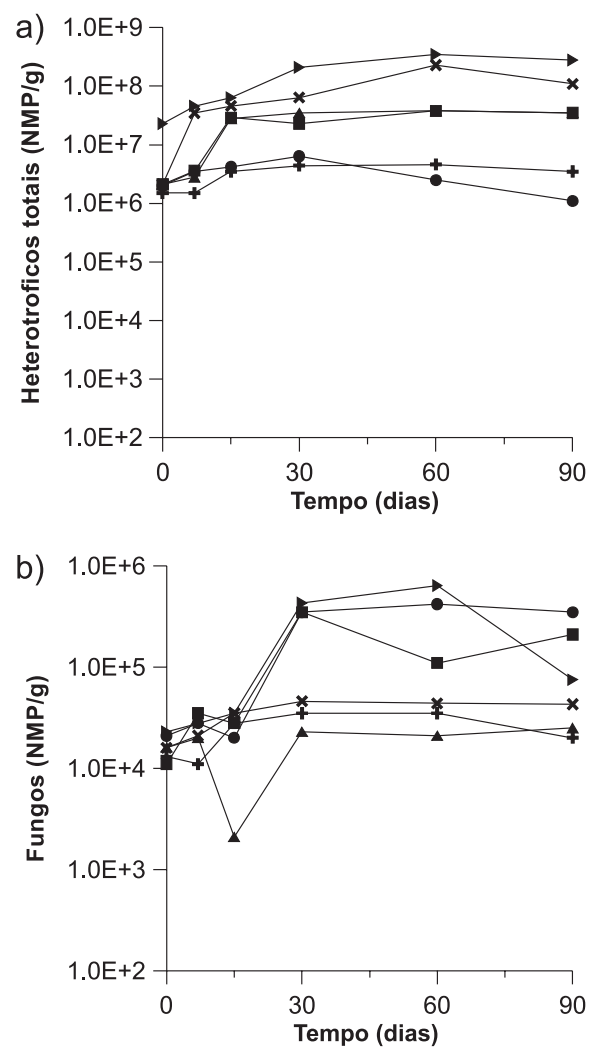

Figura 1. Estimativa do número de microrganismos presentes nos solos contaminados com óleo de pescado bruto ao longo de 90 dias de experimento. (a) Microrganismos heterotróficos totais. (b) Fungos. + Exp.1; - Exp. 2; - Exp. 3; $\triangle$ Exp. 4; Exp. 5; $\times$ Exp.6

As maiores densidades populacionais foram encontradas nos tempos entre 15 e 60 dias de processo para os solos contaminados com tolueno e entre 30 e 90 dias para os solos contaminados com óleo de pescado. No período de 60 a 90 dias foi verificada redução na concentração de microrganismos. A faixa ideal de umidade do solo para processos de biodegradação está compreendida entre 12 e $30 \% .^{22}$ Inicialmente a umidade do solo dos experimentos foi ajustada a $12 \%$. No entanto, ao longo dos dias foi verificado aumento da temperatura local, variando de 14 a $28^{\circ} \mathrm{C}$, o que pode ter favorecido a evaporação da água do solo. Além disso, semanalmente o solo foi revolvido para promover aeração ao meio, o que pode também ter auxiliado no processo de evaporação da água e favorecido a redução da concentração de microrganismos.
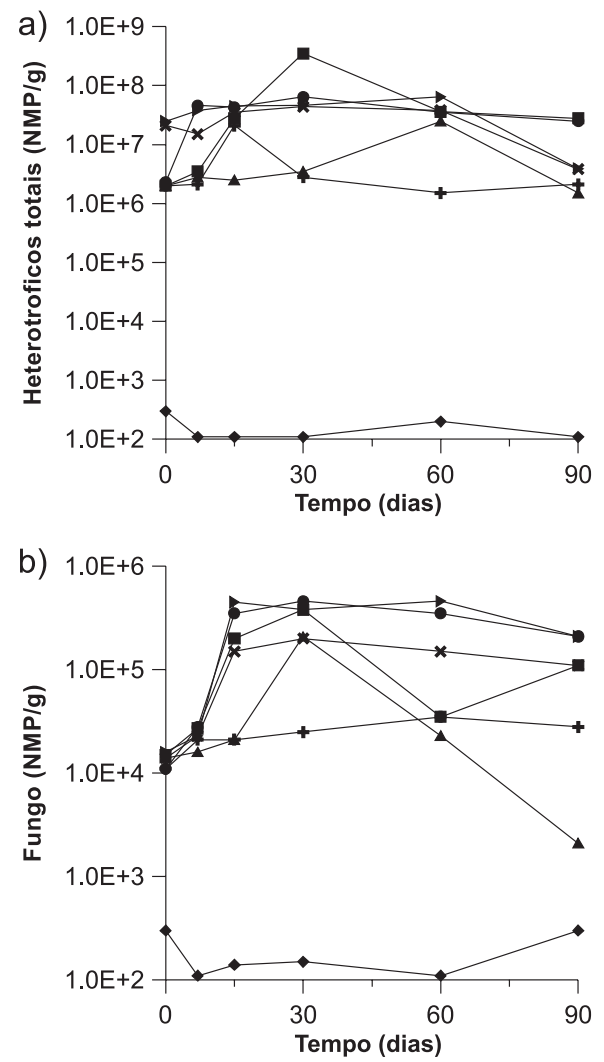

c)

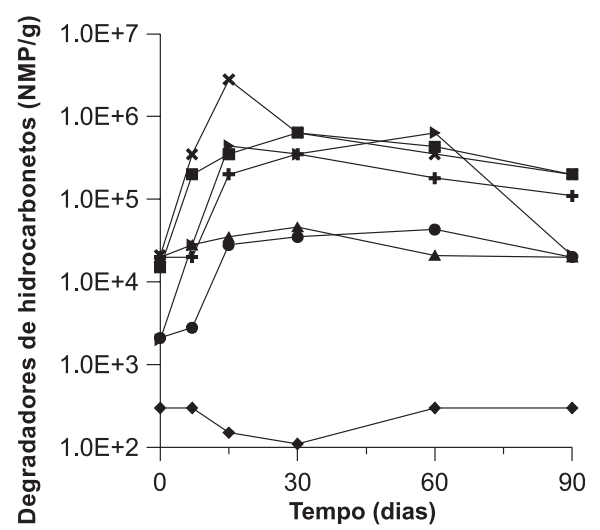

Figura 2. Estimativa do número de microrganismos presentes nos solos contaminados com tolueno ao longo de 90 dias de experimento. (a) Microrganismos heterotróficos totais. (b) Fungos. (c) Microrganismos degradadores de hidrocarbonetos. $+\operatorname{Exp} .1 ; \boldsymbol{\square} \operatorname{Exp} .2 ; \bullet \operatorname{Exp} .3 ; \boldsymbol{\Delta} \operatorname{Exp} .4 ; \operatorname{Exp} .5 ; \mathbf{x}$ Exp. 6, $\bullet$ Exp. 7

A população microbiana encontrada no experimento 1 (controle) de ambos os compostos mostrou freqüentemente ser menor que nos demais experimentos, ao longo do processo. Nas primeiras semanas não foi verificada redução considerável dos microrganismos indicando que estes não foram afetados de forma negativa com a presença dos contaminantes. Os experimentos contendo fertilizantes apresentaram as maiores densidades microbianas, mostrando que a adição de fontes de nitrogênio e fósforo aos solos estimulou o crescimento dos microrganismos.

Os experimentos adicionados de surfactantes mostraram aumento da população de microrganismos quando comparado ao experimento 1 (controle). A maior concentração de fungos foi encontrada nos experimentos contendo biossurfactante. Foi verificado o crescimento 
de Aspergillus fumigatus nos experimentos 3 e 5, o que pode ser relacionado ao fato de o biossurfactante adicionado aos solos não ter sofrido etapa prévia de esterilização, podendo ter permanecido esporos de Aspergillus fumigatus no extrato surfactante.

O experimento 7 (branco), realizado apenas para o estudo de solos contaminados com tolueno, tinha por finalidade verificar as perdas abióticas durante o processo. No entanto, de acordo com o mostrado na Figura 2, verifica-se que em 7 dias de experimento foi detectada a presença de microrganismos heterotróficos totais e fungos. Isso ocorreu, muito provavelmente, devido à exposição do solo ao ambiente local.

\section{Análises de nutrientes}

O conteúdo de nitrogênio total nos ensaios de bioestimulação $(2,5$ e 6$)$ apresentou queda pronunciada nos primeiros 45 dias de experimento. Em alguns ensaios houve aumento do conteúdo de nitrogênio no tempo entre 45 e 90 dias de processo. Este aumento pode ser relacionado à provável produção, pelos microrganismos presentes no solo, de metabólitos secundários extracelulares ao longo do tempo.

O conteúdo de nitrogênio total nos solos contaminados com óleo de pescado (Figura 1Sa - material suplementar), no período de 90 dias reduziu $0,25 \%$ ao utilizar-se bioestimulação (experimento 2), $0,20 \%$ quando se utilizou bioestimulação e dispersante (experimento 6) e $0,11 \%$, com bioestimulação e biossurfactante (experimento 5). As maiores taxas de redução foram 66,66 e $64,10 \%$ para os ensaios 6 e 2, respectivamente. Em relação aos solos contaminados com tolueno (Figura 1Sb), reduções de 0,50; 0,43 e 0,37\% no conteúdo de nitrogênio em 90 dias foram obtidas nos experimentos 5, 2 e 6, respectivamente. As maiores taxas de redução foram obtidas para os ensaios $2(89,58 \%)$ e $5(87,72 \%)$.

O conteúdo de fósforo total nos ensaios 5 e 6 reduziu ao longo do tempo. Observaram-se taxas de redução de $12,5 \%$, para o experimento contendo dispersante e bioestimulação nos solos contaminados com óleo de pescado, e 14,28 e 23,08\%, para os ensaios 5 e 6, respectivamente, nos solos contaminados com tolueno (Figura $2 \mathrm{~S}$ ). O ensaio 5 (biossurfactante e bioestimulação) apresentou altas reduções nos conteúdos de nitrogênio e fósforo e alta população microbiana, indicando que as fontes de nitrogênio e fósforo no meio foram utilizadas pelos microrganismos, favorecendo o seu desenvolvimento.

Os microrganismos necessitam de fontes de nutrientes para seu crescimento. Nitrogênio, fósforo e potássio são os principais nutrientes inorgânicos adicionados ao solo para favorecer o crescimento microbiano e, conseqüentemente, aumentar a taxa degradativa do contaminante. $\mathrm{O}$ nitrogênio pode ser adicionado na forma de uréia, cloreto de amônio ou nitrato de amônia. Estas fontes de nitrogênio são facilmente assimiladas pelo metabolismo microbiano. Já o fósforo pode ser adicionado na forma de fosfato de sódio, fosfato de potássio, sais orto-fosfórico e polifosfato. ${ }^{4}$

\section{Degradação dos contaminantes}

A Figura 3 mostra a eficiência de remoção do óleo de pescado bruto em termos de lipídios totais para os períodos de 0 a 30, 30 a 60 e 60 a 90 dias de processo. Nos primeiros 30 dias de processo foi evidenciada maior redução do teor de lipídos totais. Para avaliar o nível de degradação do óleo de pescado bruto nos ensaios, levou-se em consideração o ensaio controle (experimento 1), o qual apresentou redução de 23,07\% de lipídios totais ao longo de 90 dias de processo. Assim, os experimentos 2, 3 e 4 apresentaram redução total de 23,57; 15,47 e 17,38\%, respectivamente, no conteúdo de lipídios totais.

A análise de ácidos graxos (Tabela 3) nos extratos lipídicos

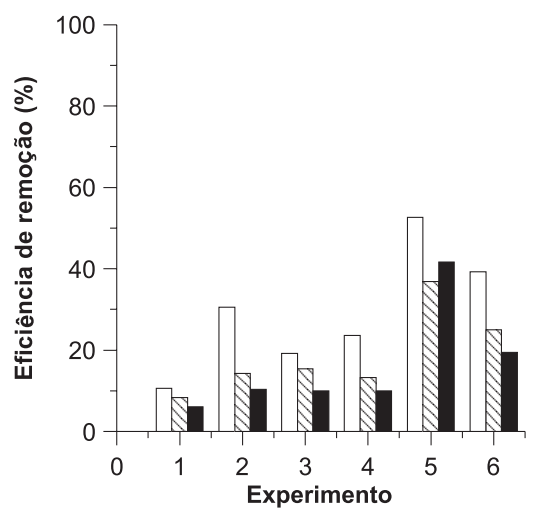

Figura 3. Eficiência de remoção de óleo de pescado bruto com base no teor de lipídios totais para diferentes intervalos de tempo. $\square$ o a 30 dias; $\square C$. 30 a 60 dias; 60 a 90 dias

Tabela 3. Composição (\%) de ácidos graxos do óleo de pescado bruto no tempo de 0 e 90 dias para os diferentes experimentos

\begin{tabular}{lccccccccc}
\hline Exp. $\begin{array}{c}\text { tempo } \\
\text { (dias) }\end{array}$ & C14:0 & C16:0 & C16:1 & C18:0 & C18:1 & C18:2 & C18:3 & C20:0 \\
\hline 1 & 0 & 0,24 & 1,36 & 0,65 & 0,48 & 1,12 & nd & 0,15 & 0,03 \\
& 90 & 0,26 & 1,39 & 0,36 & 0,34 & 0,63 & 0,03 & 0,09 & 0,03 \\
& 0 & 0,23 & 1,40 & 0,65 & 0,42 & 1,14 & 0,02 & 0,15 & 0,03 \\
2 & 90 & 0,09 & 0,67 & 0,27 & 0,19 & 0,71 & 0,06 & 0,13 & 0,02 \\
& 0 & 0,17 & 1,00 & 0,56 & 0,30 & 1,00 & 0,03 & 0,14 & 0,02 \\
3 & 90 & 0,11 & 0,81 & 0,25 & 0,23 & 0,50 & nd & 0,07 & 0,02 \\
& 0 & 0,24 & 1,37 & 0,63 & 0,47 & 1,04 & 0,02 & 0,14 & 0,03 \\
4 & 90 & 0,16 & 1,00 & 0,30 & 0,24 & 0,54 & 0,02 & 0,06 & 0,01 \\
& 0 & 0,18 & 1,17 & 0,67 & 0,45 & 1,27 & 0,05 & 0,20 & 0,03 \\
5 & 90 & 0,02 & 0,24 & 0,06 & 0,10 & 0,22 & 0,02 & 0,03 & 0,01 \\
& 0 & 0,17 & 1,17 & 0,67 & 0,35 & 1,30 & 0,05 & 0,21 & 0,03 \\
6 & 90 & 0,04 & 0,61 & 0,08 & 0,26 & 0,32 & 0,05 & 0,06 & 0,03 \\
\hline
\end{tabular}

Ácidos graxos: C14:0, ácido mirístico; C16:0, ácido palmítico; C16:1; ácido palmitoléico, C18:0, ácido esteárico; C18:1, ácido oléico; C18:2, ácido linoléico; C18:3, ácido linolênico; C20:0, ácido araquídico. nd = não detectado

mostrou haver modificação na estrutura do óleo, uma vez que apresentou redução dos teores da maioria dos ácidos graxos analisados. As reduções dos teores de ácidos graxos variaram de 0,02 a 1,05\%. Para os ensaios 1 a 4, o ácido graxo de maior quantidade presente nos extratos lipídicos no início do processo foi o ácido palmítico (C16:0). A maior redução no conteúdo de ácidos graxos ao longo do tempo para o experimento 2 foi de $0,73 \%$ de ácido palmítico (C16:0) e 0,50\% de ácido oléico (C18:1) para os experimentos 3 e 4 . Os ensaios 5 e 6 apresentaram as maiores taxas de degradação ao longo de 90 dias, alcançando reduções de 59,47 e 40,21\% no conteúdo de lipídios totais, respectivamente. O maior decréscimo no conteúdo de ácidos graxos para os experimentos 5 e 6 foi obtido para o ácido oléico (C18:1), os quais apresentaram reduções de 1,05 e $0,98 \%$, respectivamente.

O uso de dispersante químico favoreceu o processo de degradação do óleo de pescado quando comparado à utilização de biossurfactante. No entanto, ao utilizar-se biossurfactante juntamente com bioestimulante, verificou-se maior taxa de degradação. A utilização de dispersante químico juntamente com o fertilizante pode ter cau- 
sado alguma reação química, causando o retardamento do processo de degradação.

Os ensaios utilizando fertilizantes mostraram maior contagem de microrganismos, indicando que os nutrientes estimularam o crescimento microbiano. De acordo com a análise de nutrientes, verifica-se que as maiores reduções de nitrogênio foram obtidas nos experimentos 2 (bioestimulação) e 6 (bioestimulação e dispersante químico) em 90 dias de processo e para os ensaios 2 e 5 (bioestimulação e biossurfactante) em 45 dias. A utilização de biossurfactante juntamente com bioestimulante mostrou favorecer o processo de degradação, apresentando maior redução do conteúdo de óleo quando comparada aos demais tratamentos.

Os experimentos de biodegradação de tolueno em solos contaminados foram realizados durante 90 dias, sendo que em 21 dias de experimento a concentração de tolueno encontrada foi reduzida significativamente a valores menores que $3 \mathrm{mg} / \mathrm{kg}$ (Figura 4), que corresponde ao limite de detecção do método empregado. De acordo com a legislação, o valor limite de exposição de humanos ao tolueno corresponde a $78 \mathrm{ppm}(48 \mathrm{~h} / \mathrm{semana}){ }^{23}$

$\mathrm{O}$ experimento 1 foi realizado com o objetivo de verificar a capacidade dos microrganismos endógenos do solo em degradar o contaminante e o experimento 7 para verificar a quantidade de tolueno evaporada. $\mathrm{O}$ experimento 1 apresentou redução da concentração de tolueno ao longo do tempo, por vezes maior que os demais experimentos. $\mathrm{O}$ experimento 7 apresentou diminuição da concentração de tolueno ao longo do tempo, indicando que houve perdas por volatilização do composto. Durante o processo foi feito o controle da temperatura local. Nos primeiros 14 dias, a temperatura variou de 14 a $22^{\circ} \mathrm{C}$, sendo que as mais altas temperaturas alcançadas foram de 24 e $28^{\circ} \mathrm{C}$, no final do processo. As temperaturas ótimas de biodegradação de hidrocarbonetos usualmente são entre 15 e $30^{\circ} \mathrm{C} .{ }^{24}$ No entanto, devido ao fato de os experimentos serem mantidos em local aberto, estando expostos à contaminação, parte desta redução pode ter ocorrido por atividade microbiana e não somente por perdas abióticas. Segundo a análise microbiológica, crescimento microbiano foi detectado em 7 dias de experimento.

A Figura 4 mostra a eficiência de remoção do tolueno para os períodos de 0 a 4,4 a 7 e 7 a 14 dias de processo. Nos primeiros 4 dias de experimento, os solos mostraram maiores taxas de redução na concentração de tolueno nos experimentos $3(64,35 \%)$ e $1(55,85 \%)$ e apresentaram baixa eficiência de remoção $(6,95 \%)$ no experimento 4 (dispersante químico).

Entre 4 e 7 dias de processo, verifica-se que maior taxa de degradação foi obtida para os experimentos 3 (biossurfactante) e 5 (biossurfactante e biostimulação), obtendo-se valores de 97,24 e $99,19 \%$, respectivamente. A menor taxa de remoção foi obtida para o

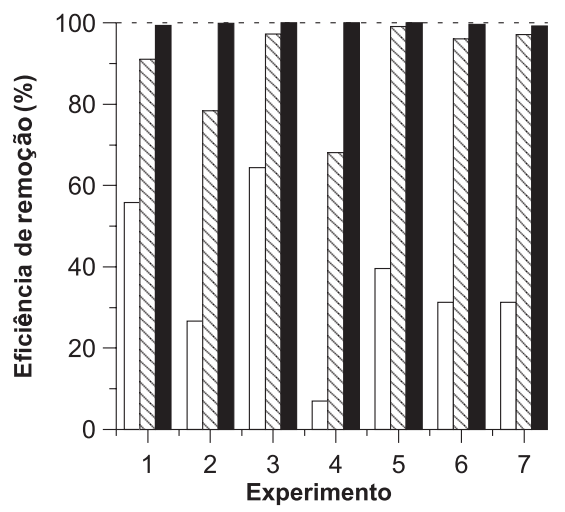

Figura 4. Eficiência de remoção de tolueno para diferentes intervalos de tempo. $\square$ o a 4 dias; V/Z4 4 a 7 dias; 7 a 14 dias experimento utilizando dispersante químico (experimento 4), o qual apresentou redução de $68,16 \%$. No período de 7 a 14 dias, redução de $100 \%$ foi obtida para os experimentos 3 (biossurfactante), 4 (dispersante) e 5 (biossurfactante e bioestimulação).

Avaliando o processo apenas durante os primeiros 7 dias, verificase que a maior remoção de tolueno foi obtida quando se utilizou biossurfactante $(99,01 \%)$ e para o experimento com biossurfactante e bioestimulação $(99,52 \%)$. Entretanto, é importante citar que o experimento com solo estéril (branco) apresentou remoção de $98,00 \%$, mostrando que a evaporação do composto contribuiu de forma expressiva na remoção do contaminante do solo, enquanto o experimento 1 apresentou remoção de $96,06 \%$. Assim, evidencia-se que a utilização de biossurfactantes, apesar da diminuta fração de remoção, mostrou contribuir para a eliminação do composto.

Os experimentos utilizando biossurfactante apresentaram taxas de remoção mais elevadas em 4, 7 e 14 dias de processo.

Diferentes surfactantes têm sido testados em diferentes solos e poluentes e têm mostrado estimular a degradação de poluentes orgânicos. ${ }^{9}$ A capacidade de um surfactante em aumentar rapidamente a biodegradação de um composto orgânico depende do grau para o qual a biodisponibilidade orgânica é aumentada pelo surfactante. Em estudos anteriores foi verificado leve aumento na biodegradação induzido por biossurfactantes para 4 constituintes testados da gasolina (tolueno, $m$-xileno, naftaleno e 1,2,4-trimetilbenzeno), sendo a maior degradação observada para o 1,2,4-trimetilbenzeno, o qual foi degradado em 7 dias na presença de biossurfactante e em 12 dias para o controle. ${ }^{25}$

No período de 7 dias, a taxa de remoção de tolueno ao utilizarse bioestimulação foi de $84,17 \%$, com dispersante químico foi de $70,37 \%$, e com dispersante químico juntamente com bioestimulação foi $97,29 \%$. Ao utilizar-se biossurfactante ou dispersante químico juntamente com bioestimulação, a taxa de remoção aumentou quando comparada com os experimentos em que se utilizou somente surfactantes. A maior população de microrganismos foi encontrada nos experimentos contendo surfactantes e bioestimulação, quando comparados aos experimentos contendo apenas surfactantes. A adição de biossurfactantes mostrou aumentar a biodisponibilidade do contaminante ao microrganismo, uma vez que na sua presença houve aumento da degradação do composto. Além disso, altas reduções no conteúdo de nitrogênio foram encontradas para os experimentos contendo surfactantes e bioestimulação.

Os dados mostraram que a adição de nutrientes ao meio favoreceu o crescimento microbiano. Em estudos realizados com solos contaminados com $5 \%(\mathrm{p} / \mathrm{p})$ de borra oleosa proveniente da indústria de petróleo, foi alcançada taxa de degradação de $66 \%$ em 90 dias de processo ao se utilizar tratamento com nutrientes inorgânicos. ${ }^{26}$ A adição de fertilizantes inorgânicos como fonte de nutrientes para os microrganismos é interessante, pois fornece nutrientes ao solo de forma menos agressora e mais econômica. Muitos estudos têm relatado que a adição de nitrogênio e fósforo aumenta a biodegradação de diversos compostos, sem que sejam observados danos ao meio ambiente. No entanto, em estudos anteriormente realizados visando o estabelecimento das relações nutricionais adequadas para processos de biorremediação de solos contaminados, foi verificado que dosagens excessivas de nutrientes, principalmente de nitrogênio, podem interferir negativamente no processo de biodegradação. ${ }^{27}$ Diversos estudos vêm sendo realizados para determinar as concentrações ótimas de nutrientes a serem adicionadas. A taxa ótima reportada na literatura é 100:15:3 para a biodegradação de hidrocarbonetos. ${ }^{6,28} \mathrm{Em}$ estudos de biodegradação de hidrocarbonetos de petróleo em solos contaminados, foi verificada taxa de redução de $94,5 \%$ no experimento controle (solo contaminado) e de 95,5 e 96,8\% em solos com adição de fertilizantes inorgânicos. ${ }^{6}$ 
O estudo da biodegradação de compostos tóxicos, como o tolueno, é importante visto que os maiores problemas de contaminação de solos e aqüíferos causados por derramamentos de gasolina são atribuídos aos hidrocarbonetos denominados BTEX (benzeno, tolueno, etilbenzeno e xileno). Estes são os constituintes da gasolina mais solúveis e com maior potencial de lixiviação. ${ }^{29}$

Ao analisar os processos de biodegradação de tolueno e óleo de pescado bruto em solos contaminados, verifica-se que em ambos os processos se obteve maior remoção dos compostos ao se utilizar biossurfactante juntamente com bioestimulante. A utilização de fertilizantes aumentou a população microbiana, mostrando ser uma alternativa interessante para processos de bioestimulação. $\mathrm{O}$ processo de descontaminação dos solos ocorreu mais rapidamente para o composto de origem mineral que para o de origem animal, sendo que o fenômeno de evaporação influenciou de forma significativa na remoção do composto. No caso de um derramamento de tolueno, a utilização da técnica de biodegradação in situ, juntamente com processo de tratamento de vapores, mostra-se mais adequada, tendo em vista a curta duração do processo. Do ponto de vista econômico, o tratamento no próprio local do derrame apresentase mais vantajoso. O composto de origem animal demorou mais tempo para ser removido quando comparado ao de origem mineral, no entanto, o processo de biodegradação mostrou-se eficiente para sua remoção.

\section{CONCLUSÕES}

A utilização de biossurfactante produzido por fermentação em estado sólido a partir do fungo filamentoso Aspergillus fumigatus favoreceu o processo de degradação de compostos de origem mineral e animal em solos contaminados.

O processo de bioestimulação mostrou favorecer o crescimento de microrganismos endógenos do solo e aumentar a taxa degradativa dos compostos.

A maior eficiência de remoção do óleo de pescado bruto foi alcançada no experimento contendo biossurfactante e bioestimulação $(59,47 \%)$ em 90 dias de processo. Em relação aos experimentos com tolueno, a maior taxa de remoção (100\%) foi obtida em 14 dias de processo para os ensaios contendo biossurfactante, dispersante químico e biossurfactante com bioestimulação. Contudo, os resultados mostraram que a taxa de evaporação do composto apresentou influência pronunciada na remoção do mesmo no solo, mostrando taxa de remoção de 98,00\% em 7 dias. Assim, verifica-se que para os experimentos de biodegradação de tolueno, a utilização de biossurfactante e bioestimulante mostrou-se dispensável, tendo em vista a reduzida taxa de remoção em comparação ao experimento controle. No entanto, sua utilização mostrou favorecer a remoção, mesmo em baixas quantidades.

O biosurfactante mostrou-se eficaz no processo de descontaminação de solos, favorecendo a remoção do poluente quando utilizado juntamente com bioestimulante. Tendo em vista sua menor toxicidade e a possibilidade de obtenção a partir de substratos renováveis e de baixo custo, a utilização de biossurfactantes, quando comparados aos surfactantes químicos, apresenta-se vantajosa tanto do ponto de vista econômico quanto ambiental.

\section{MATERIAL SUPLEMENTAR}

As Figuras $1 \mathrm{~S}$ e $2 \mathrm{~S}$ apresentando o conteúdo de nitrogênio total e fósforo total, respectivamente, nos experimentos com solos contaminados com óleo de pescado e tolueno nos dias 0, 45 e 90 dias, encontram-se no material suplementar disponível gratuitamente em http://quimicanova.sbq.org.br, na forma de arquivo PDF.

\section{AGRADECIMENTOS}

À COPESUL, Companhia Petroquímica do Sul, e CAPES, Coordenação de Aperfeiçoamento de Pessoal de Nível Superior, pelo apoio financeiro para a realização deste trabalho.

\section{REFERÊNCIAS}

1. Boopathy, R.; Bioresour. Technol. 2000, 74, 63.

2. Cury, J. C.; Dissertação de Mestrado, Universidade de São Paulo, Brasil, 2002.

3. Morais, E. B.; Tauk-Tornisielo, S. M.; Arq. Inst. Biol. 2004, 71, 272.

4. Rizzo, A. C. L.; Leite, S. G. F.; Soriano, A. U.; Santos, R. L. C.; Sobral, L. G. S.; Série Tecnologia Ambiental, STA-37, CETEM/MCT, 2006.

5. Esposito, E.; Azevedo, J. L.; Fungos: uma introdução à biologia, bioquímica e biotecnologia, Educs: Caxias do Sul, 2004.

6. Sarkar, D.; Ferguson, M.; Datta, R.; Birnbaum, S.; Environ. Pollut. 2005, 136, 187.

7. Balba, M. T.; Al-Awadhi, N.; Al-daher, R.; J. Microbiol. Methods 1998, 32,155 .

8. Mulligan, C. C.; Yong, R. N.; Gibbs, B. F.; Eng. Geology 2001, 60, 371.

9. Volkering, F.; Breure, A. M.; Rulkens, W. H.; Biodegradation 1998, 8, 401.

10. Makkar, R. S.; Cameotra, S. S.; Appl. Microbiol. Biotechnol. 2002, 58, 428.

11. Suguio, K.; Introdução à Sedimentologia, Ed. Edgard Blücher: São Paulo, 1973.

12. Ilori, M. O.; Amobi, C. J.; Odocha, A. C.; Chemosphere 2005, 61, 985.

13. Martins, V. G.; Kalil, S. J.; Bertolin, T. E.; Costa, J. A. V.; Z. Naturforsch., C: J. Biosci. 2006, 61, 721.

14. PETROBRAS; Critérios para Homologação de Dispersantes Químicos, CONTEC- Comissão de Normas Técnicas - N 2530, Rio de Janeiro, 1995.

15. AOCS; Official Method Ce 1f-96, Determination of cis- and trans- Fatty Acids in Hydrogenated and Refined Oils and Fats by Capillary GLC, 1997.

16. EPA 5021-96; Volatile organic compounds in soils and other solid matrices using equilibrium headspace analysis, 1996

17. EPA 8015-B-96; Nonhalogenated organics using GC/FID, 1996.

18. Braddock, J. F.; Catterall, P. H.; Bioremed. J. 1999, 3, 81.

19. Bento, F. M.; Camargo, F. A. O.; Okeke, B. C.; Frankenberger, W. T.; Bioresour. Technol. 2005, 96, 1049.

20. APHA; Standard Methods for the Examination of Water and Wastewater, $19^{\text {th }}$ ed., Washington, 1995.

21. AOAC; Official Methods of Analysis of International, $16^{\text {th }}$ ed., Arlington: Virginia, 1995.

22. EPA 510-B-94-003; EPA 510-B-95-007; EPA 510-R-04-002; How to Evaluate Alternative Cleanup Technologies for Underground Storage Tank Sites: A Guide for Corrective Action Plan Reviewers, 1994.

23. BRASIL; Portaria MTb 3214/78, NR 15, 1978.

24. Thomassin-Lacroix, E. J. M.; Reimer, K. J.; Mohn, W. W.; Appl. Microbiol. Biotechnol. 2002, 59, 551.

25. Miller, R. M. Em Bioremediation, Science and Aplications; Turco, R. F.; Skipper, H. D., eds.; SSSA Special Publication, 43, 1995.

26. Vasudevan, N.; Rajaram, P.; Environ. Int. 2001, 26, 409.

27. Soriano, A. U.; Relatório Técnico- RT 08/2001, CETEM/MCT, 2001.

28. Liebeg, E. W.; Cutright, T. J.; International Biodeterioration and Biodegradation 1999, 44, 55.

29. Barker, J. F.; Hubbard, C. E.; Lemon, L. A.; Ground Water Manage. 1990, 4, 113. 


\section{BIODEGRADAÇÃO DE TOLUENO E ÓLEO DE PESCADO EM SOLOS IMPACTADOS UTILIZANDO SURFACTANTES QUÍMICO E BIOLÓGICO}

Vanessa Sacramento Cerqueira e Jorge Alberto Vieira Costa*

Escola de Química e Alimentos, Universidade Federal do Rio Grande, CP 474, 96201-900 Rio Grande - RS, Brasil
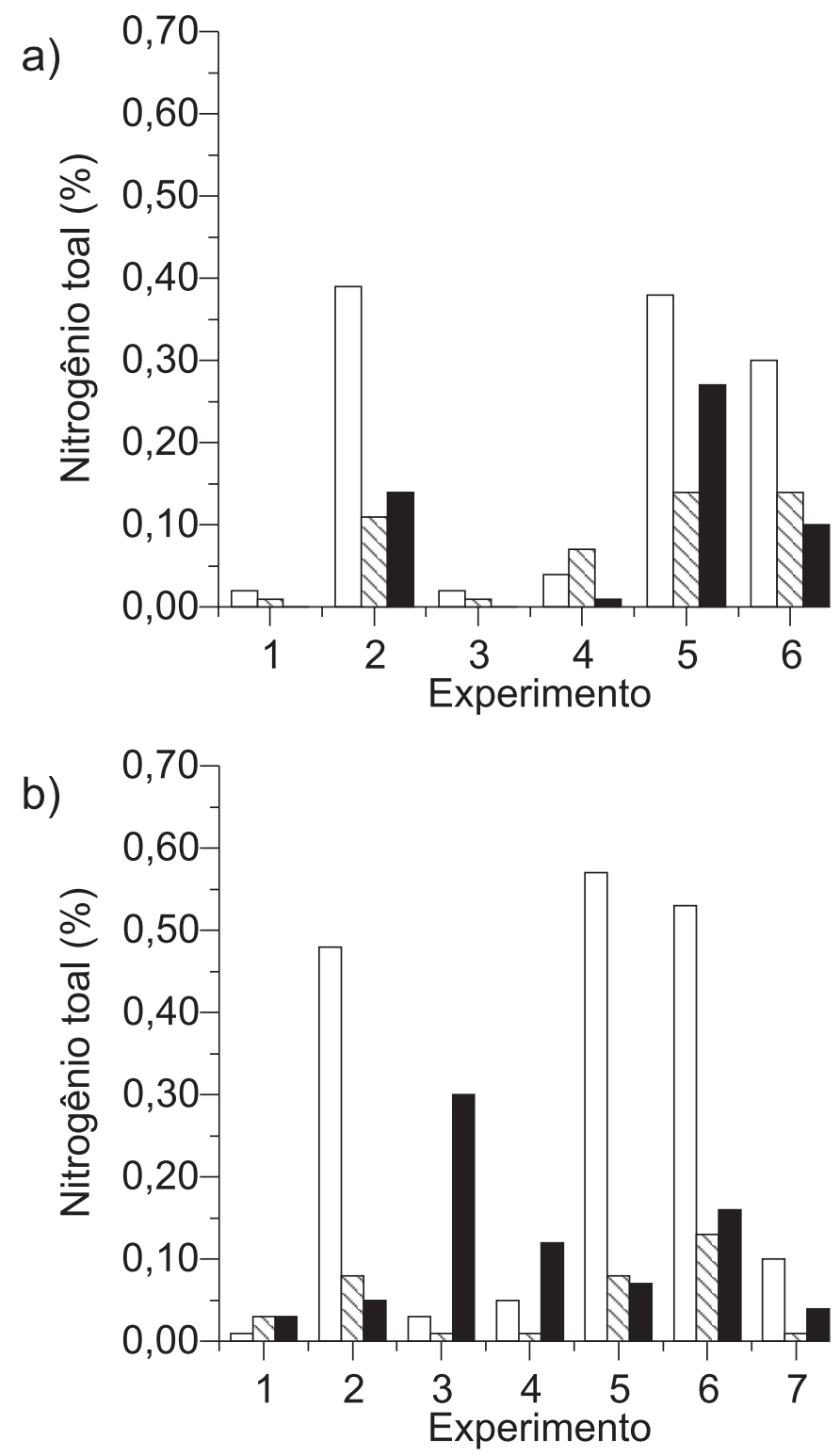

Figura 1S. Conteúdo de nitrogênio total nos experimentos (a) solos contaminados com óleo de pescado. (b) solos contaminados com tolueno. $\square$ ( dia, $\square / Z$. 45 dias e 90 dias 

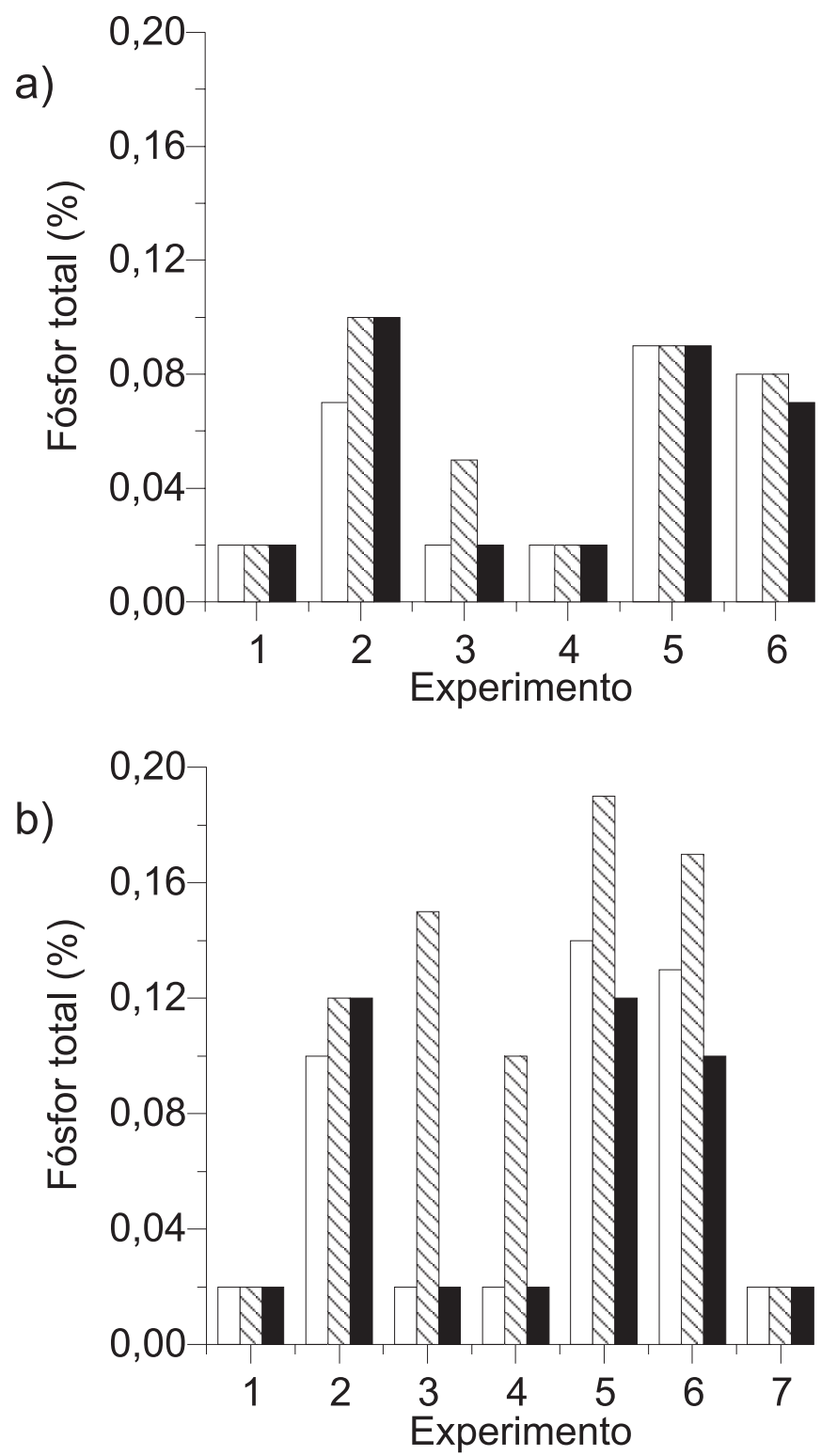

Figura 2S. Conteúdo de fósforo total nos experimentos (a) solos contaminados com óleo de pescado. (b) solos contaminados com tolueno. $\square$ 0 dia, $Q / Z$ 45 dias e 90 dias 